\title{
Supported Nanosized $\alpha$-FeOOH Improves Efficiency of Photoelectro-Fenton Process with Reaction-Controlled pH Adjustment for Sustainable Water Treatment
}

\author{
Chuan Wang, ${ }^{1}$ Hong Liu, ${ }^{1,2}$ Zhimin Sun, ${ }^{3}$ Jian Huang, ${ }^{2}$ and Yang Liao ${ }^{2}$ \\ ${ }^{1}$ Chongqing Institute of Green and Intelligent Technology, Chinese Academy of Sciences, Chongqing 401122, China \\ ${ }^{2}$ School of Chemistry and Chemical Engineering, Sun Yat-sen University, Guangzhou 510275, China \\ ${ }^{3}$ Guangzhou Municipal Engineering Design \& Research Institute, Guangzhou 510060, China
}

Correspondence should be addressed to Hong Liu, liuhong@cigit.ac.cn

Received 27 July 2012; Accepted 12 September 2012

Academic Editor: Jiaguo Yu

Copyright (C) 2012 Chuan Wang et al. This is an open access article distributed under the Creative Commons Attribution License, which permits unrestricted use, distribution, and reproduction in any medium, provided the original work is properly cited.

\begin{abstract}
The overall photoelectro-Fenton (PE-Fenton) process for water treatment with neutral initial $\mathrm{pH}$ includes three steps of $\mathrm{pH}$ reduction, $\mathrm{PE}-$ Fenton reaction, and $\mathrm{pH}$ elevation. Reaction-controlled $\mathrm{pH}$ adjustment (RCpA), which utilizes the intrinsic electrochemical reactions instead of chemical addition, has been employed to lower the $\mathrm{pH}$, maintain the lowered $\mathrm{pH}$ for the Fenton reaction, and recover the $\mathrm{pH}$ for final effluent discharge. This study demonstrated that the overall efficiency of this sustainable PE-Fenton process was improved by rapidly recycling the iron substance. Nanosized iron oxide was prepared and employed to ensure such rapid recycling. SEM and XRD results showed that the as-prepared iron oxide was $\alpha$-FeOOH with $20 \mathrm{~nm}$ in size. The experimental results of dimethyl phthalate (DMP) degradation showed that diatomite-supported $\alpha-\mathrm{FeOOH}(\mathrm{N}-\alpha-\mathrm{FeOOH} /$ diatomite) could efficiently reduce the DMP concentration and total organic carbon. Furthermore, compared with $\mathrm{Fe}^{3+}$, the $\mathrm{N}-\alpha-$ $\mathrm{FeOOH}$ /diatomite saved $160 \mathrm{~min}$ for iron settlement at $20 \mathrm{mg} \mathrm{L}^{-1} \mathrm{DMP}$ concentration. Also, with the increment in the initial DMP concentration, extra energy consumed by the individual step of PE-Fenton reaction using the $\mathrm{N}$ - $\alpha$-FeOOH/diatomite became negligible compared with that using free iron ions with the increment in the initial DMP concentration. This development is expected to be a major step of the PE-Fenton process with RCpA towards actual water treatment.
\end{abstract}

\section{Introduction}

The cathodic electro-Fenton reaction (E-Fenton) with electrogenerated $\mathrm{H}_{2} \mathrm{O}_{2}$ and added $\mathrm{Fe}^{2+}$ as an advanced oxidation process (AOP) has recently been developed on the basis of a well-established Fenton's reagent [1-4] for the degradation of recalcitrant organic pollutants in aqueous media. The cathodic and coupled anodic reactions of the E-Fenton reaction are expressed as follows [4-6]:

$$
\begin{aligned}
& \mathrm{O}_{2}+2 \mathrm{H}^{+}+2 \mathrm{e} \longrightarrow \mathrm{H}_{2} \mathrm{O}_{2} \quad \text { (cathodic reaction) } \\
& \mathrm{H}_{2} \mathrm{O} \longrightarrow \frac{1}{2} \mathrm{O}_{2}+2 \mathrm{H}^{+}+2 \mathrm{e} \quad \text { (anodic reaction) }
\end{aligned}
$$

During this process, the electrogenerated $\mathrm{H}_{2} \mathrm{O}_{2}$ interacts with the added $\mathrm{Fe}^{2+}$ to form nonselective and highly active hydroxyl radicals that destroy the organic substrates. Many reports have demonstrated that the E-Fenton process is a promising AOP for water purification [7-9].

Two hurdles must be surpassed for the development for a realistic application of the E-Fenton process. The first is the narrow $\mathrm{pH}$ required for the Fenton reaction [10-12]. The medium $\mathrm{pH}$ for the Fenton reaction must be maintained within the narrow range of 2.0-4.0 to preclude the iron precipitate. This $\mathrm{pH}$ limitation obviously requires chemical addition of an acid and a base to obtain the desired $\mathrm{pH}$, essentially hampering the realistic application of the PEFenton reaction. The second is the running off of iron ions. Solid iron oxides can substitute iron ions and photo energy is simultaneously inputted to mediate the E-Fenton process, also known as the photoelectron-Fenton (PE-Fenton) process $[3,8,13-15]$. Without input of electricity, this system is called photo-Fenton system [16-18]. Furthermore, nanosized iron oxides have been observed to exhibit higher 
reactivity. However, they present a difficulty for separation from the aqueous phase after use given their small size and fine dispersion in the solution. Therefore, the problems with $\mathrm{pH}$ conditioning and iron recovery need to be solved to develop a more efficient PE-Fenton process.

For the $\mathrm{pH}$-conditioning obstacle, a reaction-controlled $\mathrm{pH}$ adjustment (RCpA) mechanism has been found, which can be explored to preclude the chemical addition and thereby bring sustainability to the associated water treatment process [19]. Briefly, spatial separation of the cathode and anode chambers ensures the use of the $\mathrm{OH}^{-}$generated in the cathode (1) and $\mathrm{H}^{+}$in the anode (2). The former increases the $\mathrm{pH}$, whereas the latter decreases the $\mathrm{pH}$. A combination of the two chambers ensures the maintenance of a low $\mathrm{pH}$. The strategy can obtain varied $\mathrm{pH}$ for all-pH conditioning without any chemical addition. Naturally, such mechanism works in the PE-Fenton process. Therefore, any measure that serves to separate the nanosized iron oxide rapidly for recovery is desirable in the PE-Fenton process with RCpA for sustainable water treatment.

The present study attempts to prepare nanosized iron oxide and support it on diatomite in the PE-Fenton process with RCpA to boost the overall efficiency significantly by shortening the duration of iron settlement. Diatomite, abundant in many areas of the world, has unique physical characteristics, such as high permeability and porosity, small particle size, and high surface area [20]. It is commonly used in the fields of catalysis and environmental purification as an environment friendly support material. Dimethyl phthalate (DMP), which is representative of dialkyl phthalate esters (DPEs), belongs to the family of endocrine-disrupting chemicals [21-24]. It was used as a model organic substrate in the study to assess the efficiency of the PE-Fenton process rapidly. The efficiency of the iron settlement was also evaluated through the settling time.

\section{Experimental Section}

2.1. Chemicals and Reagents. Except for acetonitrile (Dima Technology, Inc., Richmond Hill, Ontario, CA, USA), which is a high-performance liquid chromatography (HPLC) grade reagent, all other chemicals employed, such as DMP, $\mathrm{FeSO}_{4} \cdot 7 \mathrm{H}_{2} \mathrm{O}$, and $\mathrm{H}_{2} \mathrm{O}_{2}$, were of analytical grade and used as obtained from Xilong Chemical, Inc. (Shantou, Guangdong, China). In all experiments, double-distilled water was used. The water used to prepare the $\mathrm{Fe}^{2+}$ solution was bubbled with high-purity $\mathrm{N}_{2}$ gas (99.99\%) for $30 \mathrm{~min}$ before solution preparation. Sulfuric acid and sodium hydroxide were used at $0.1 \mathrm{M}$ concentration to obtain the initial $\mathrm{pH}\left(\mathrm{pH}_{0}\right)$ of the solution.

\subsection{Preparation and Characterization of Nanosized Iron Oxide} Supported on Diatomite. The iron-oxide-supported diatomite was prepared. $\mathrm{FeCl}_{3}$ solution at $0.5 \mathrm{mM}$ concentration was immersed with diatomite for $2 \mathrm{~h}$ and filtered to separate the $\mathrm{Fe}^{3+} /$ diatomite from the supernatant. The latter was discarded, and the former was washed with water repeatedly until the $\mathrm{Cl}^{-}$was completely removed, as confirmed by a precipitation test using $\mathrm{AgNO}_{3}$ solution. Finally, the $\mathrm{Fe}^{3+} /$ diatomite was heated to $400^{\circ} \mathrm{C}$ for $5 \mathrm{~h}$ at a temperatureincreasing rate at $10^{\circ} \mathrm{C} \mathrm{min}{ }^{-1}$. The theoretical iron content in the diatomite was calculated to be $5 \%$. For comparison, unsupported iron oxide powder was also prepared in the absence of diatomite. The as-prepared samples were then observed by scanning electron microscopy (SEM) using a Philips Quanta $400 \mathrm{FE}$ environmental scanning electromicroscope (FEI, Holland) coupled with an INCA energy dispersive X-Ray spectrometer (EDS, Oxford, UK) to obtain the atomic composition of the products. X-ray diffraction (XRD) was employed to investigate the chemical composition of the samples at $45 \mathrm{kV}$ and $30 \mathrm{~mA}$ using a D/MAX 2200 VPC (RIGAKU, Japan) equipped with a graphite monochromator $(\mathrm{Cu} \mathrm{K} \alpha,=1.54056 \AA)$.

2.3. Experimental Procedure. The design of the quartz electrochemical reactor with a graphite cathode $\left(15 \mathrm{~cm}^{2}\right)$ and a Pt anode $\left(1.0 \times 1.0 \mathrm{~cm}^{2}\right)$ is presented in Figure 1. The reactor consisted of three chambers: a common chamber (undivided chamber) with both anode and cathode and two divided chambers (anodic chamber and cathodic chamber) connected by a bipolar membrane $[25,26]$. Each chamber had an effective volume of $120 \mathrm{~mL}$ and a height of $15 \mathrm{~cm}$. In the reactor, $\mathrm{H}_{2} \mathrm{O}_{2}$ was generated by purging air onto the cathode at a flow rate of $100 \mathrm{~mL} \mathrm{~min}^{-1}$ controlled by a needle valve. DMP degradation via the PE-Fenton reaction was performed. Sodium sulfate solution ( $0.05 \mathrm{M}$ concentration) was used as the electrolyte. An $8 \mathrm{~W}$ near-UV lamp with a primary wavelength of $365 \mathrm{~nm}$ was employed to illuminate the cathode in the common and cathodic chambers. A PS-1 potentiostat/galvanostat (Zhongfu Corrosion and Protection Co., Ltd., Beijing, China) was employed to apply a cathodic current to the electrode system.

In the three-step PE-Fenton process, three-step $\mathrm{pH}$ conditioning by RCpA was also performed. In the first step, the $\mathrm{pH}$ was lowered below 4.0 through the anodic reaction. Keeping the low $\mathrm{pH}$ constant was the second step, and the third step was bringing the $\mathrm{pH}$ to neutral. Organic degradation occurred in the second step and continued into the third step. In this study, we focused on comparing the DMP degradation using free iron ions and supported nanosized iron oxide in the second step.

The as-prepared iron oxide was used in the PE-Fenton process (see Figure 1). For comparison, ferric ions were also used as the iron substance in the PE-Fenton process, during which iron sludge was formed due to the increased $\mathrm{pH}$. In the third step of the PE-Fenton process, the iron substances in the form of iron sludge or solid iron oxide were relocated from the cathodic chamber to the anodic chamber for reuse. The settling time for the iron oxide and the iron sludge formed from $\mathrm{Fe}^{3+}$ was recorded. DMP solution was put into the cathode chamber for PE-Fenton degradation. During the PE-Fenton reaction, $1.0 \mathrm{~mL}$ sample was withdrawn for analysis, and $10 \mu \mathrm{L}$ of methanol was injected into the sample to quench any potential radical reaction before the measurement the DMP concentration, while no chemical was injected to measure the total organic carbon (TOC). 


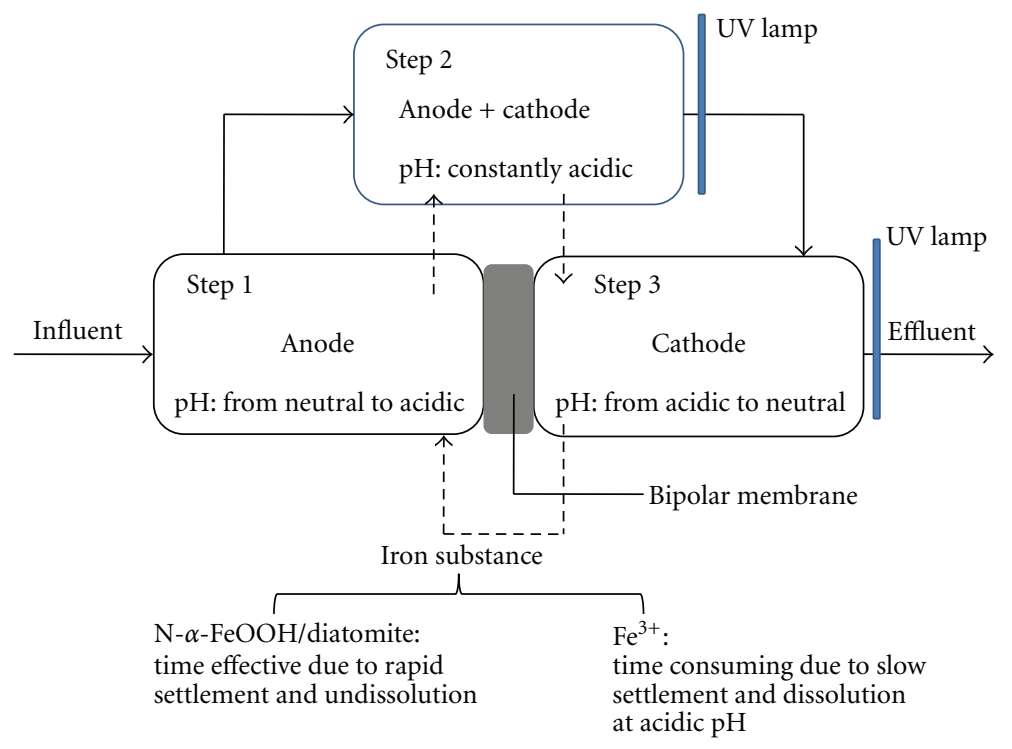

FIGURE 1: Schematic of the PE-Fenton process with reaction-controlled $\mathrm{pH}$ adjustment (RCpA).
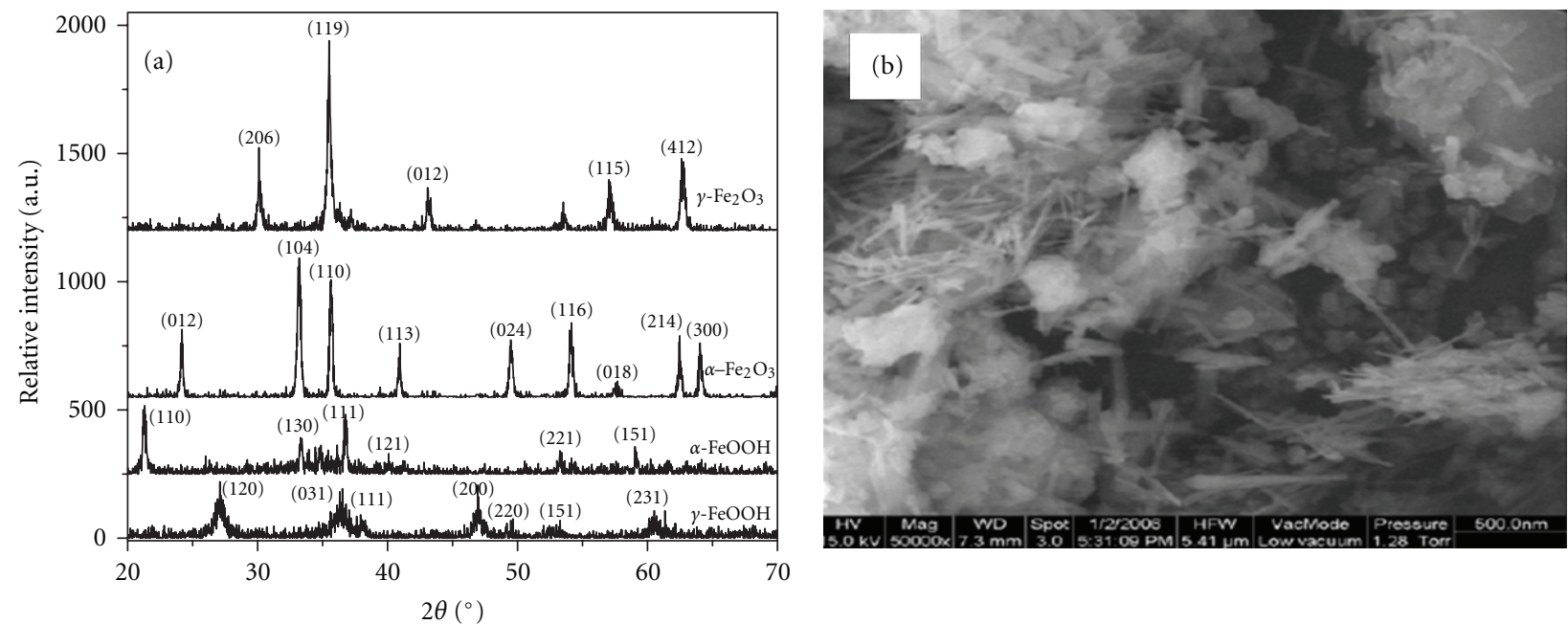

FIgURE 2: (a) XRD patterns of unsupported iron oxides and (b) SEM image of N- $\alpha$-FeOOH.

2.4. Chemical Analysis. The DMP concentration was analyzed by HPLC (Techcomp, LC 2130, Shanghai, China) equipped with a reverse-phase column (Waters, XTerra MS C-18, $5 \mu \mathrm{m}$ ) and a UV detector. The mobile phase was composed of acetonitrile and water (50:50), and the measurement wavelength for the UV detector was set to $276 \mathrm{~nm}$. The TOC concentration was measured using a TOC analyzer (Shimadzu 5000A) equipped with an autosampler. For the measurement of total iron, the $\mathrm{Fe}^{3+}$ in the solution was initially reduced to $\mathrm{Fe}^{2+}$ by hydroxylamine hydrochloride, then quantified via the light absorption intensity of the complex formed between the $\mathrm{Fe}^{2+}$ and 1,10-phenanthroline at $508 \mathrm{~nm}$ [27] using a UV-VIS spectrophotometer (TU1810, Universal Analysis, Beijing, China).

\section{Results and Discussion}

3.1. Characterization of the Iron Oxide Samples. Figure 2(a) shows the results of the XRD investigation of the as-prepared unsupported samples at different calcination temperatures. Iron oxide in the form of $\gamma-\mathrm{FeOOH}$ was obtained at the low calcination temperature of $65^{\circ} \mathrm{C}$. By increasing the calcination temperature, the $\gamma$ - $\mathrm{FeOOH}$ was transformed to $\alpha$-FeOOH, then to $\alpha-\mathrm{Fe}_{2} \mathrm{O}_{3}$, and finally to $\gamma-\mathrm{Fe}_{2} \mathrm{O}_{3}$.

\subsection{Efficiency of the PE-Fenton Reaction in DMP Degradation} Using Nanosized $\alpha-\mathrm{FeOOH}$. A set of DMP degradation experiments via the PE-Fenton reaction with RCpA was performed to evaluate the efficiency of the PE-Fenton reaction 


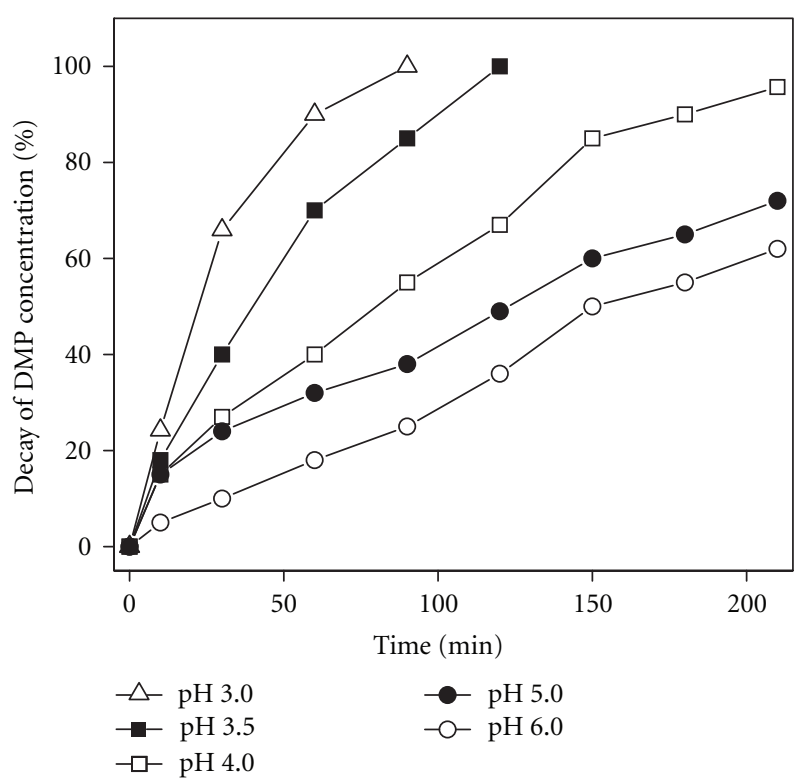

(a)

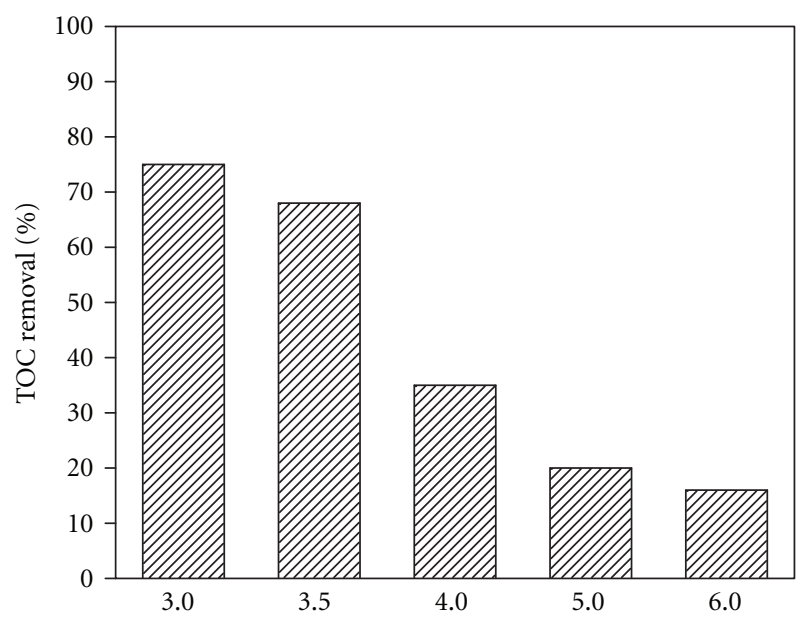

(b)

Figure 3: PE-Fenton degradation of DMP at $20 \mathrm{mg} \mathrm{L}^{-1}$ in the common chamber at different $\mathrm{pH}$ using $\mathrm{N}-\alpha$-FeOOH/diatomite. (a) Decay of DMP concentration (\%) and (b) TOC removal after $210 \min (\%)$.

in the common chamber using the four types of iron oxides. $\mathrm{N}-\alpha-\mathrm{FeOOH}$ was the most active in DMP degradation (data not shown). The morphology of the $\mathrm{N}-\alpha-\mathrm{FeOOH}$ was then observed by SEM, and the results are shown in Figure 2(b). $\mathrm{N}-\alpha-\mathrm{FeOOH}$ was leaf-like with one dimension at nanoscale.

Another set of DMP degradation experiments via the PE-Fenton reaction with RCpA was subsequently performed to evaluate the efficiency of the PE-Fenton reaction in the common chamber using $\mathrm{N}-\alpha-\mathrm{FeOOH}$ at initial $\mathrm{pH}$ of 3.0, $3.5,4.0,5.0$, and 6.0. In the common chamber, the $\mathrm{OH}^{-}$ in (1) and $\mathrm{H}^{+}$in (2) neutralized each other to maintain the solution $\mathrm{pH}$. The results of the DMP degradation are shown in Figure 3(a). The decrease in DMP concentration in the Fenton reaction depended on the $\mathrm{pH}$. Thus, a high $\mathrm{pH}$ was

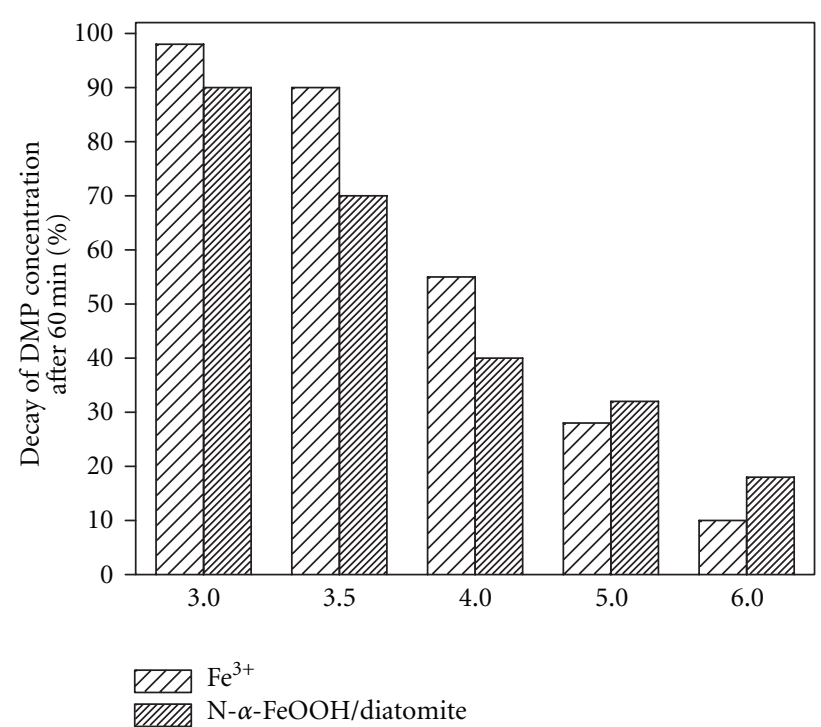

FIGURE 4: Decay of DMP at $20 \mathrm{mg} \mathrm{L}^{-1}$ initial concentration after 60 min of the PE-Fenton reaction using $\mathrm{Fe}^{3+}$ ions and $\mathrm{N}-\alpha-\mathrm{FeOOH}$ at different $\mathrm{pHs}$.

detrimental for the PE-Fenton reaction from $\mathrm{pH} 3.5$ to 6.0 . A 100\% decay of DMP concentration was obtained within $90 \mathrm{~min}$ at $\mathrm{pH} 3.0$ and within $120 \mathrm{~min}$ at $\mathrm{pH}$ 3.5. At a $\mathrm{pH}$ above 4.0, the decrease in DMP concentration slowed down significantly, and only $62 \%$ of the DMP was reduced. TOC removal was detected after $210 \mathrm{~min}$ of the PE-Fenton reaction (Figure $3(\mathrm{~b})$ ). With increasing $\mathrm{pH}$, TOC removal decreased significantly from $75 \%$ at $\mathrm{pH} 3.0$ to $16 \%$ at $\mathrm{pH} 6.0$.

For comparison, an optimal dose of free $\mathrm{Fe}^{3+}$ ions at $1.0 \mathrm{mM}$ was used as the iron substance for the PE-Fenton reaction. After $10 \mathrm{~min}$ reaction at $\mathrm{pH}$ above 4.0, iron precipitate was formed. The DMP concentrations were detected after $60 \mathrm{~min}$. The DMP concentrations at $60 \mathrm{~min}$ under different $\mathrm{pHs}$ were compared in Figure 4. At $\mathrm{pH} 3.0,3.5$, and 4.0, the DMP degradation efficiency in terms of $\mathrm{Fe}^{3+}$ concentration was higher than those for $\mathrm{N}-\alpha-\mathrm{FeOOH}$. However, the opposite case was observed at $\mathrm{pH} 5.0$ and 6.0. That was to say, at pH 5.0 and 6.0, the DMP removal efficiency using $\mathrm{N}-\alpha$-FeOOH after $60 \mathrm{~min}$ was higher than that using $\mathrm{Fe}^{3+}$. This result implied that at higher $\mathrm{pH}$, the $\mathrm{Fe}^{3+}$ precipitation impeded its competitiveness compared with the $\mathrm{N}-\alpha$-FeOOH. In addition, DMP degradation due to the coagulation of ferric hydroxide was negligible [19].

3.3. Supported and Unsupported $N-\alpha-F e O O H$. The activities of the supported and unsupported $\mathrm{N}-\alpha$-FeOOH in DMP degradation by the PE-Fenton reaction were further evaluated. Two sets of experiments were conducted with the two iron substances to degrade $20 \mathrm{mg} \mathrm{L}^{-1} \mathrm{DMP}$ at $\mathrm{pH}$ 3.5. Each set included six experiments with different dosages of the iron materials. After 90 minutes of the reaction time, the D MP concentrations in the samples were measured (Figure 5). Supported $\mathrm{N}-\alpha$-FeOOH on diatomite exhibited markedly higher activity than unsupported $\mathrm{N}-\alpha-\mathrm{FeOOH}$. Under 


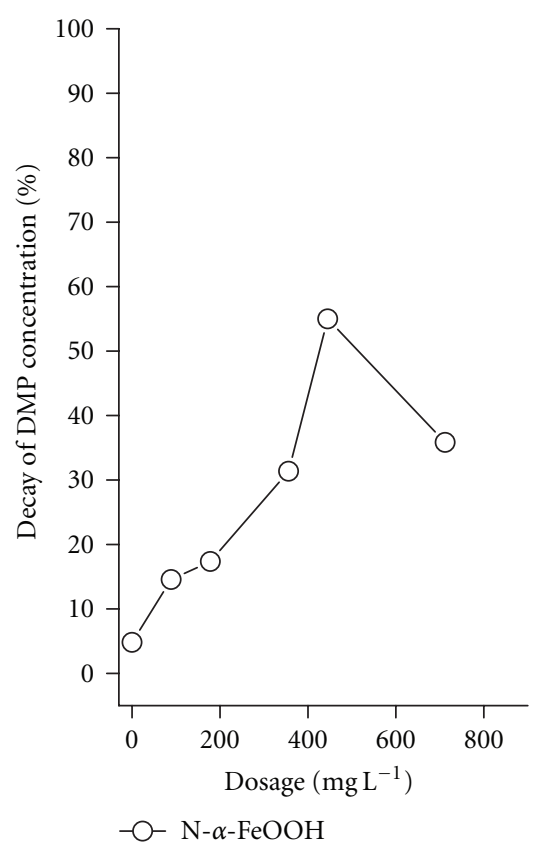

(a)

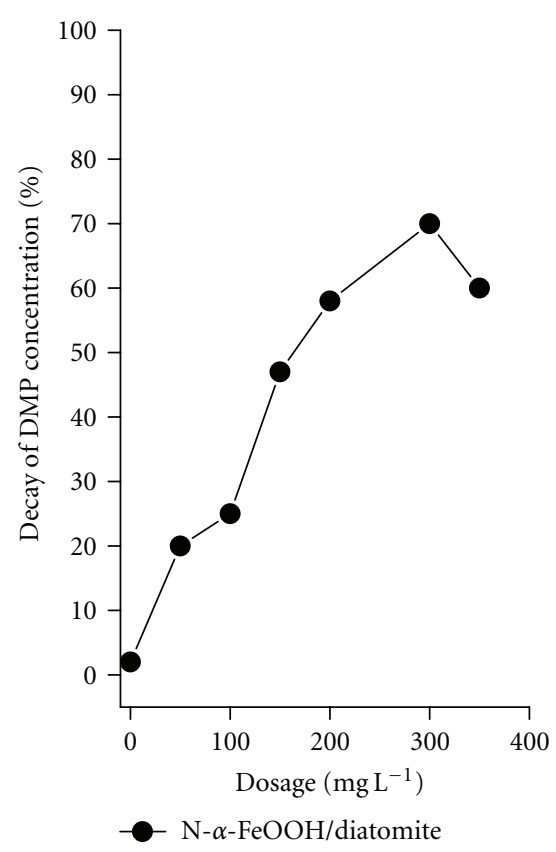

(b)

FIGURE 5: Decay of DMP at $20 \mathrm{mg} \mathrm{L}^{-1}$ initial concentration after $60 \mathrm{~min}$ of the PE-Fenton reaction using (a) unsupported N- $\alpha$-FeOOH and (b) $\mathrm{N}-\alpha-\mathrm{FeOOH} /$ diatomite a $\mathrm{pH} 3.5$.

an optimal dosage of unsupported $\mathrm{N}-\alpha-\mathrm{FeOOH}$, the DMP concentration decreased by 55\%; for the supported $\mathrm{N}-\alpha$ $\mathrm{FeOOH}$ on diatomite, the DMP concentration decreased by $70 \%$. Since it was quite difficult for unsupported $\mathrm{N}-\alpha$ $\mathrm{FeOOH}$ to settle, this study focused on comparing the activities of $\mathrm{N}-\alpha-\mathrm{FeOOH} /$ diatomite and $\mathrm{Fe}^{3+}$ without paying any further attention to the unsupported $\mathrm{N}-\alpha$-FeOOH.

3.4. Duration of pH Elevation and Reduction and Iron Settlement. During the $\mathrm{pH}$ increase, the iron substances settled as ferric hydroxide or $\mathrm{N}-\alpha-\mathrm{FeOOH} /$ diatomite for separation and recovery from the aqueous solution. During the process of $\mathrm{pH}$ decrease, the ferric hydroxide dissolved. Besides the efficiency of the PE-Fenton reaction (Step 2) with RCpA, the overall efficiency of the PE-Fenton process also clearly relied on the duration of $\mathrm{pH}$ elevation and reduction steps.

Theoretically, the duration of $\mathrm{pH}$ increase equals that of $\mathrm{pH}$ decrease. The durations are listed in Table 1. It could be seen that during the step of $\mathrm{pH}$ reduction, the duration of iron settlement using $\mathrm{Fe}^{3+}$ was $45 \mathrm{~min}$, slightly longer than that $(40 \mathrm{~min})$ using $\mathrm{N}-\alpha-\mathrm{FeOOH} /$ diatomite. As the $\mathrm{pH}$ decreased, the ferric hydroxide gradually dissolved. In contrast, such consumption of $\mathrm{H}^{+}$was precluded when $\mathrm{N}-\alpha$ $\mathrm{FeOOH} /$ diatomite was used. Thus, $\mathrm{pH}$ reduction using $\mathrm{Fe}^{3+}$ demanded more $\mathrm{H}^{+}$and slightly prolonged the operation time.

In the step of $\mathrm{pH}$ elevation, the duration of $\mathrm{pH}$ adjustment using $\mathrm{Fe}^{3+}$ reached $45 \mathrm{~min}$, which was also slightly longer $(40 \mathrm{~min})$ than when using $\mathrm{N}-\alpha-\mathrm{FeOOH} /$ diatomite. The prolonged interval was attributed to the formation of ferric hydroxide that consumed $\mathrm{OH}^{-}$during the process of
TABle 1: Duration of the steps in the PE-Fenton process with RCpA using different iron substances (current density, $6 \mathrm{~mA} \mathrm{~cm}^{-2} ; \mathrm{N}-\alpha$ FeOOH/diatomite, $500 \mathrm{mg} \mathrm{L}^{-1}$; free iron, $25 \mathrm{mg} \mathrm{L}^{-1}$ ).

\begin{tabular}{lcc}
\hline Step & \multicolumn{2}{c}{$\begin{array}{c}\text { Duration of steps (min) } \\
\mathrm{N}-\alpha \text {-FeOOH/diatomite }\end{array}$} \\
\hline pH decrease & 45 & 40 \\
PE-Fenton reaction & 75 & 100 \\
pH increase & 45 & 40 \\
Iron settlement & 180 & 15 \\
\hline Total time* & 300 & 140 \\
\hline
\end{tabular}

${ }^{*} \mathrm{pH}$ decrease and $\mathrm{pH}$ increase proceeded simultaneously, and time was included for an individual step; the time for iron settlement was included in the $\mathrm{pH}$ increase as the time for $\mathrm{pH}$ increase was longer than the settlement, otherwise, the latter included the former.

$\mathrm{pH}$ increase. Furthermore, ferric hydroxide settled very slowly. As shown in Table 1, even if the $\mathrm{pH}$ increased to 7.0, the duration of ferric hydroxide settlement took as long as $180 \mathrm{~min}$. $\mathrm{OH}^{-}$production via (1) occurred more slowly compared with via chemical addition. Thus, the ferric hydroxide particulates were finer and flocculation did not occur. In contrast, the duration of $\mathrm{N}-\alpha$-FeOOH/diatomite settlement was only $15 \mathrm{~min}$. Besides, DMP degradation using $\mathrm{Fe}^{3+}$ and $\mathrm{N}-\alpha-\mathrm{FeOOH} /$ diatomite in the second step of the PE-Fenton reaction required 75 and $100 \mathrm{~min}$, respectively. Therefore, the settlement time of the iron substances played a vital role in improving the efficiency of the PE-Fenton process with RCpA. Accordingly, the overall PE-Fenton process with RCpA using $\mathrm{N}-\alpha-\mathrm{FeOOH} /$ diatomite was more 


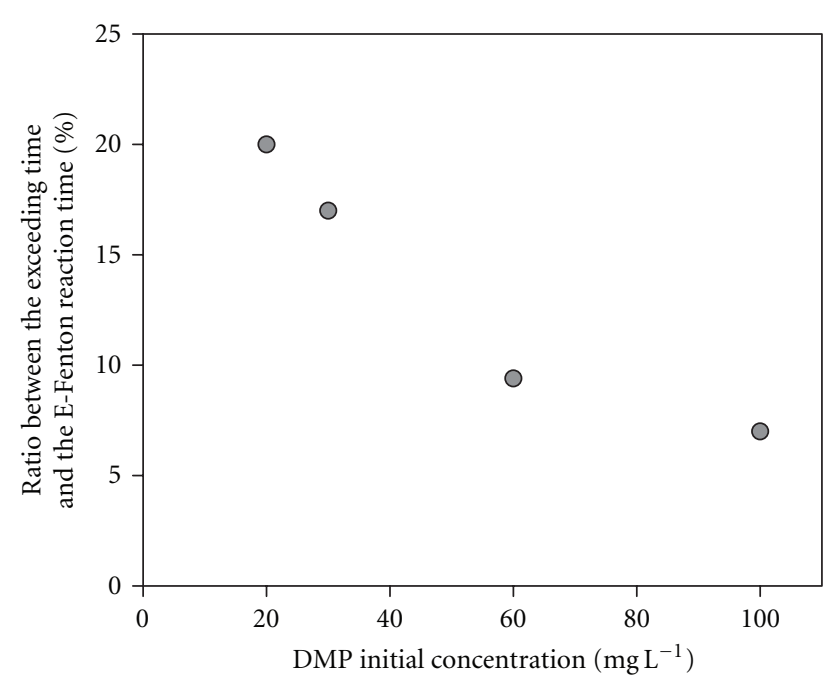

Figure 6: The proportion of the excess time to the duration of the $\mathrm{PE}-\mathrm{Fenton}$ reaction using $\mathrm{N}-\alpha-\mathrm{FeOOH} /$ diatomite (current density, $6 \mathrm{~mA} \mathrm{~cm}^{-2}$, and $\mathrm{pH} 3.5$ ).

efficient than that using $\mathrm{Fe}^{3+}$, because 160 min was saved in the present system.

3.5. Efficiency of the Reuse of Iron Substances. Following iron settlement, the iron substances can be recovered and reused. Thus, the application of this process is beneficial and environmentally safe from an engineering point of view. Interestingly, no significant decrease in the DMP degradation efficiency via the PE-Fenton process was observed either using the recycled $\mathrm{N}-\alpha-\mathrm{FeOOH} /$ diatomite or the recycled $\mathrm{Fe}^{3+}$ at $\mathrm{pH} 3.0$ or 3.5. This finding is in agreement with previous reports [19].

3.6. Energy Efficiency of the PE-Fenton Reaction Steps. Table 1 also shows that although the durations of the iron settlement and the overall process were significantly shortened by using $\mathrm{N}-\alpha-\mathrm{FeOOH} /$ diatomite, the durations of the individual steps of the PE-Fenton reaction to degrade the DMP were prolonged. Since these steps consumed energy, assessing the energy efficiency using the two different iron substances was necessary.

The duration of the steps of the PE-Fenton reaction using $\mathrm{N}-\alpha$-FeOOH/diatomite was $100 \mathrm{~min}$, whereas it was only 75 min using $\mathrm{Fe}^{3+}$. The extra 25 min was spent for the consumption of electricity. Under the conditions we established, the current was $0.050 \mathrm{~A}$, and the voltage was $2.0 \mathrm{~V}$. The extra energy for the employment of $\mathrm{N}-\alpha$-FeOOH/diatomite was thus calculated to be $0.075 \mathrm{Wh}$. Compared with the total energy consumption of $0.225 \mathrm{Wh}$ using $\mathrm{Fe}^{3+}$, using $\mathrm{N}-\alpha-\mathrm{FeOOH} /$ diatomite for the PE-Fenton reaction consumed $33.3 \%$ additional energy at a DMP concentration of $20 \mathrm{mg} \mathrm{L}^{-1}$ degradation of different concentrations of DMP was performed, and the durations obtained for the complete decay of DMP via the PE-Fenton reaction. The average additional time ranged from $20 \mathrm{~min}$ to $25 \mathrm{~min}$.
The proportion of the excess time to the duration of the PE-Fenton reaction using $\mathrm{N}-\alpha$-FeOOH/diatomite could be obtained, as shown in Figure 6. Interestingly, this ratio decreased from $20 \%$ at $20 \mathrm{mg} \mathrm{L}^{-1}$ initial DMP concentration to $7.0 \%$ at $100 \mathrm{mg} \mathrm{L}^{-1}$ initial DMP concentration. Thus, with increasing initial DMP concentration, compared with using $\mathrm{Fe}^{3+}$, the energy efficiency of the PE-Fenton reaction using $\mathrm{N}-\alpha-\mathrm{FeOOH} /$ diatomite increased. Once the DMP concentration reached $100 \mathrm{mg} \mathrm{L}^{-1}$, the added energy was less than $10 \%$. Thus, although extra energy was consumed by using $\mathrm{N}-\alpha$-FeOOH/diatomite compared with using $\mathrm{Fe}^{3+}$, the percentage of additional energy consumption became negligible as the substrate concentration increased.

\section{Conclusion}

In using $\mathrm{RCpA}$ in the PE-Fenton process for sustainable water treatment, increasing the overall efficiency of the process is important. In this study, supported nanosized iron oxide appeared to be a suitable alternative that maintains high activity and exhibits viable recyclability. The $\mathrm{N}-\alpha$ $\mathrm{FeOOH} /$ diatomite exhibited slightly lower activity than $\mathrm{Fe}^{3+}$ at lower $\mathrm{pH}$, but as the $\mathrm{pH}$ increased to 5.0 , the $\mathrm{N}-\alpha$ $\mathrm{FeOOH} /$ diatomite activity was higher. Since the second step of the PE-Fenton reaction occurred in acidic solution at $\mathrm{pH} 3.5$, the time consumed for this step using $\mathrm{N}-\alpha$ $\mathrm{FeOOH} /$ diatomite was longer than that using $\mathrm{Fe}^{3+}$ and thus extra energy was consumed in using $\mathrm{N}-\alpha$-FeOOH. However, increasing the substrate concentration to $100 \mathrm{mg} \mathrm{L}^{-1}$ caused the extra energy to become negligible. More importantly, the overall duration of the PE-Fenton process using $\mathrm{N}-\alpha$ $\mathrm{FeOOH} /$ diatomite was significantly shorter than that using the $\mathrm{Fe}^{3+}$. In our system, $160 \mathrm{~min}$ was conserved from the 300 min overall PE-Fenton process. The findings in this study imply that for any practical application of the PE-Fenton process in sustainable water treatment, the operation time and degradation efficiency, as well as the energy consumption, should be carefully balanced.

\section{Acknowledgments}

This work was supported by the Natural Science Foundation of China (Project nos. 21077071, 50978260, 51208539, and 51178129) and Chongqing Science \& Technology Commission (no. CSTC 2ZR11HD030).

\section{References}

[1] E. Neyens and J. Baeyens, "A review of classic Fenton's peroxidation as an advanced oxidation technique," Journal of Hazardous Materials, vol. 98, no. 1-3, pp. 33-50, 2003.

[2] J. J. Pignatello, E. Oliveros, and A. MacKay, "Advanced oxidation processes for organic contaminant destruction based on the fenton reaction and related chemistry," Critical Reviews in Environmental Science and Technology, vol. 36, no. 1, pp. 1-84, 2006.

[3] E. Brillas, E. Mur, R. Sauleda et al., "Aniline mineralization by AOP's: anodic oxidation, photocatalysis, electro-Fenton and 
photoelectro-Fenton processes," Applied Catalysis B, vol. 16, no. 1, pp. 31-42, 1998.

[4] M. A. Oturan, J. Peiroten, P. Chartrin, and A. J. Acher, "Complete destruction of p-Nitrophenol in aqueous medium by electro-fenton method," Environmental Science and Technology, vol. 34, no. 16, pp. 3474-3479, 2000.

[5] J. Casado, J. Fornaguera, and M. I. Galán, "Mineralization of aromatics in water by sunlight-assisted Electro-Fenton technology in a pilot reactor," Environmental Science and Technology, vol. 39, no. 6, pp. 1843-1847, 2005.

[6] E. Brillas, J. C. Calpe, and J. Casado, "Mineralization of 2,4D by advanced electrochemical oxidation processes," Water Research, vol. 34, no. 8, pp. 2253-2262, 2000.

[7] S. S. Abu Amr and H. A. Aziz, "New treatment of stabilized leachate by ozone/Fenton in the advanced oxidation process," Waste Management, vol. 32, no. 9, pp. 1693-1698, 2012.

[8] A. El-Ghenymy, S. Garcia-Segura, R. M. Rodríguez et al., "Optimization of the electro-Fenton and solar photoelectroFenton treatments of sulfanilic acid solutions using a prepilot flow plant by response surface methodology," Journal of Hazardous Materials, vol. 221-222, pp. 288-297, 2012.

[9] V. J. P. Vilar, J. M. S. Moreira, A. Fonseca et al., "Application of Fenton and solar photo-Fenton processes to the treatment of a sanitary landfill leachate in a pilot plant with CPCs," Journal of Advanced Oxidation Technologies, vol. 15, no. 1, pp. 107-116, 2012.

[10] R. G. Zepp, B. C. Faust, and J. Holgné, "Hydroxyl radical formation in aqueous reactions $(\mathrm{pH} \mathrm{3-8)}$ of iron(II) with hydrogen peroxide: the photo-fenton reaction," Environmental Science and Technology, vol. 26, no. 2, pp. 313-319, 1992.

[11] E. Lipczynska-Kochany, G. Sprah, and S. Harms, "Influence of some groundwater and surface waters constituents on the degradation of 4-chlorophenol by the Fenton reaction," Chemosphere, vol. 30, no. 1, pp. 9-20, 1995.

[12] M. L. Kremer, "The fenton reaction. Dependence of the rate on $\mathrm{pH}$," Journal of Physical Chemistry A, vol. 107, no. 11, pp. 1734-1741, 2003.

[13] S. Irmak, H. I. Yavuz, and O. Erbatur, "Degradation of 4chloro-2-methylphenol in aqueous solution by electro-Fenton and photoelectro-Fenton processes," Applied Catalysis B, vol. 63, no. 3-4, pp. 243-248, 2006.

[14] B. Boye, M. M. Dieng, and E. Brillas, "Anodic oxidation, electro-Fenton and photoelectro-Fenton treatments of 2,4,5-trichlorophenoxyacetic acid," Journal of Electroanalytical Chemistry, vol. 557, pp. 135-146, 2003.

[15] E. Brillas, M. A. Baños, M. Skoumal, P. L. Cabot, J. A. Garrido, and R. M. Rodríguez, "Degradation of the herbicide 2,4DP by anodic oxidation, electro-Fenton and photoelectroFenton using platinum and boron-doped diamond anodes," Chemosphere, vol. 68, no. 2, pp. 199-209, 2007.

[16] X. R. Zhao, L. H. Zhu, Y. Y. Zhang et al., "Removing organic contaminants with bifunctional iron modified rectorite as efficient adsorbent and visible light photo-Fenton catalyst," Journal of Hazardous Materials, vol. 215, pp. 57-64, 2012.

[17] X. M. Zhou, J. Y. Lan, G. Liu et al., "Facet-mediated photodegradation of organic dye over hematite architectures by visible light," Angewandte Chemie International Edition, vol. 51, pp. 178-182, 2012.

[18] M. Hartmann, S. Kullmann, and H. Keller, "Wastewater treatment with heterogeneous Fenton-type catalysts based on porous materials," Journal of Materials Chemistry, vol. 20, no. 41, pp. 9002-9017, 2010.
[19] H. Liu, C. Wang, X. Li, X. Xuan, C. Jiang, and H. N. Cui, "A novel electro-Fenton process for water treatment: reactioncontrolled $\mathrm{pH}$ adjustment and performance assessment," Environmental Science and Technology, vol. 41, no. 8, pp. 29372942, 2007.

[20] H. E. G. M. M. Makr, "Diatomite: its characterization, modification and applications," Asian Journal Materias Science, vol. 2, no. 3, pp. 121-136, 2010.

[21] C. A. Staples, D. R. Peterson, T. F. Parkerton, and W. J. Adams, "The environmental fate of phthalate esters: a literature review," Chemosphere, vol. 35, no. 4, pp. 667-749, 1997.

[22] A. Wang and J. Chi, "Phthalic acid esters in the rhizosphere sediments of emergent plants from two shallow lakes," Journal of Soils and Sediments, vol. 12, no. 7, pp. 1189-1196, 2012.

[23] C. Zhang and Y. Wang, "Removal of dissolved organic matter and phthalic acid esters from landfill leachate through a complexation-flocculation process," Waste Management, vol. 29, no. 1, pp. 110-116, 2009.

[24] H. Yan and G. Pan, "Increase in biodegradation of dimethyl phthalate by Closterium lunula using inorganic carbon," Chemosphere, vol. 55, no. 9, pp. 1281-1285, 2004.

[25] C. Huang and T. Xu, "Electrodialysis with bipolar membranes for sustainable development," Environmental Science and Technology, vol. 40, no. 17, pp. 5233-5243, 2006.

[26] T. Xu, "Ion exchange membranes: state of their development and perspective," Journal of Membrane Science, vol. 263, no. 1-2, pp. 1-29, 2005.

[27] American Public Health Association/American Water Works Association/Water Environment Federation, Standard Methods For the Examination of Water and Wastewater, American Public Health Association/American Water Works Association/Water Environment Federation, Washington, DC, USA, 19th edition, 1995. 


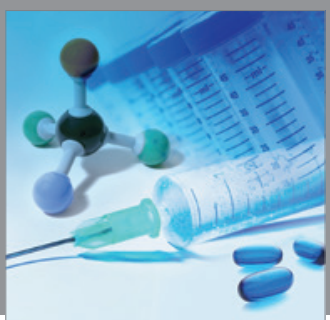

International Journal of

Medicinal Chemistry

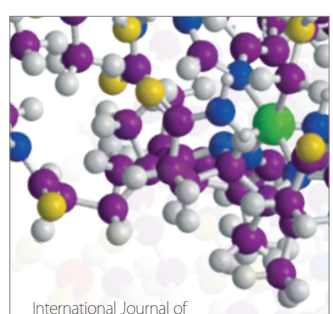

Carbohydrate Chemistry

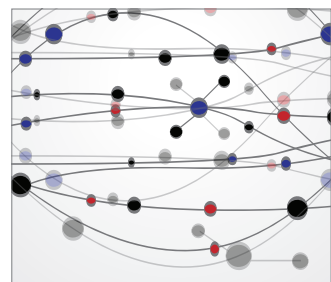

The Scientific World Journal
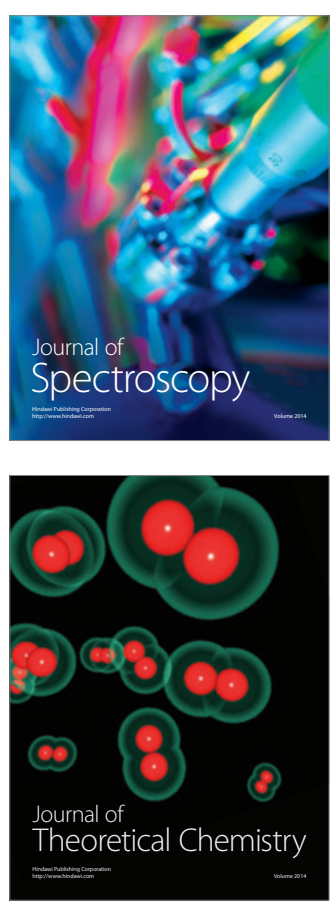
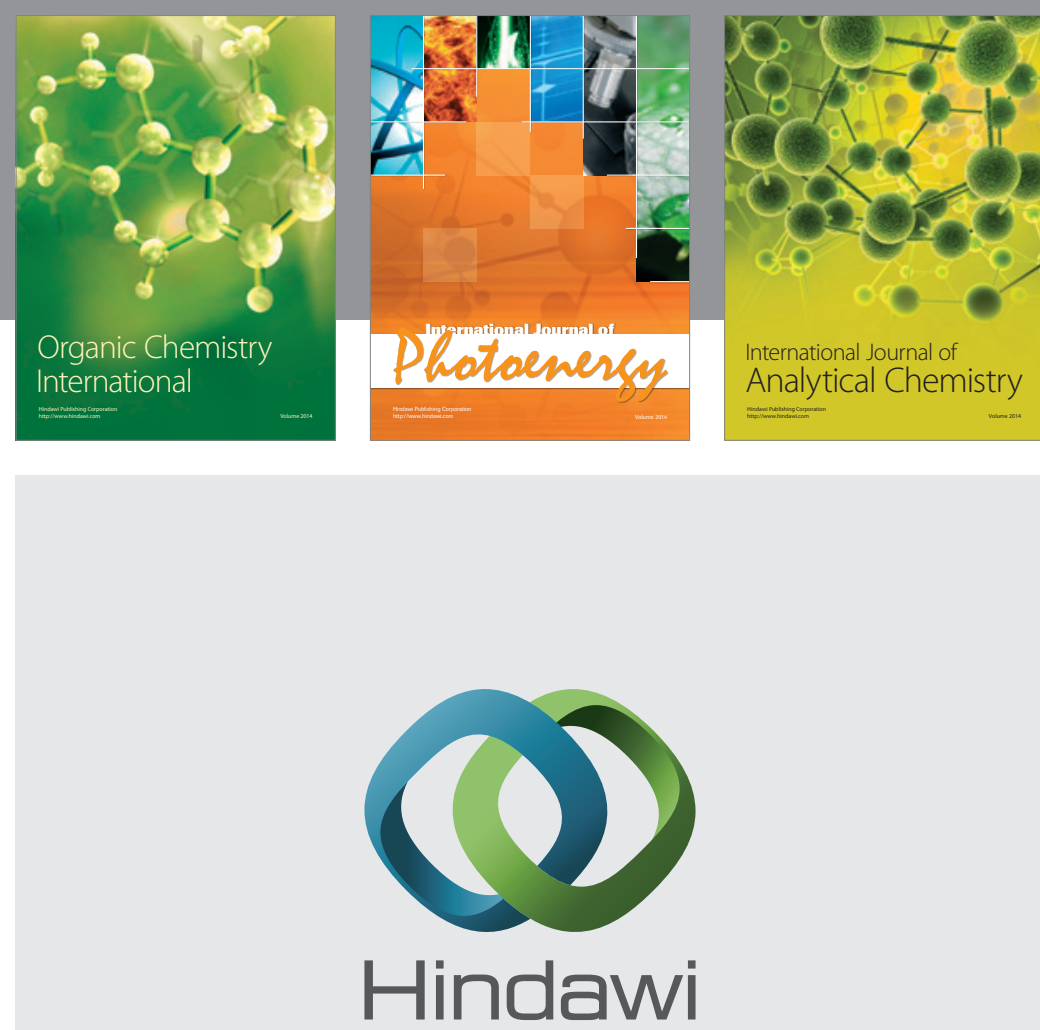

Submit your manuscripts at

http://www.hindawi.com
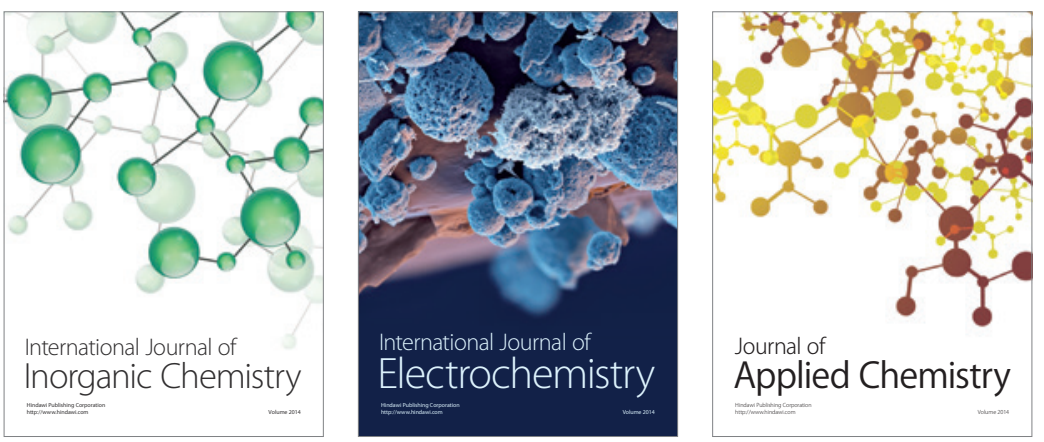

Journal of

Applied Chemistry
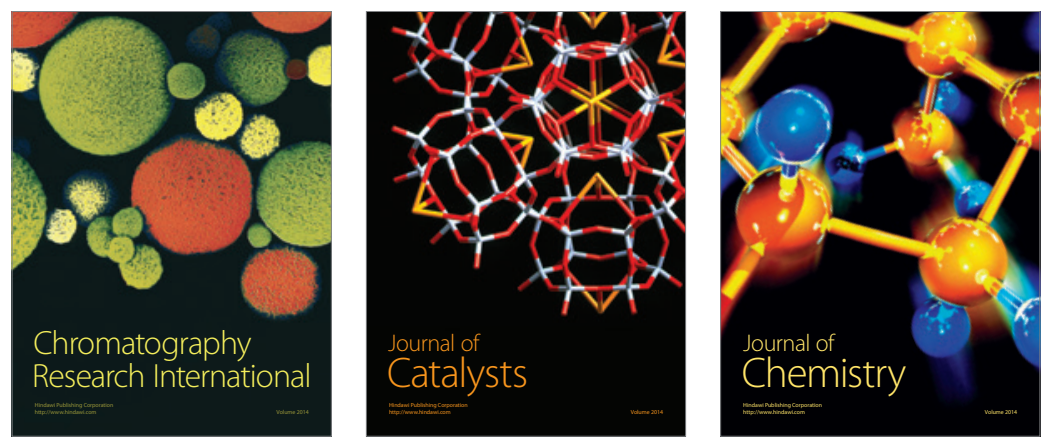
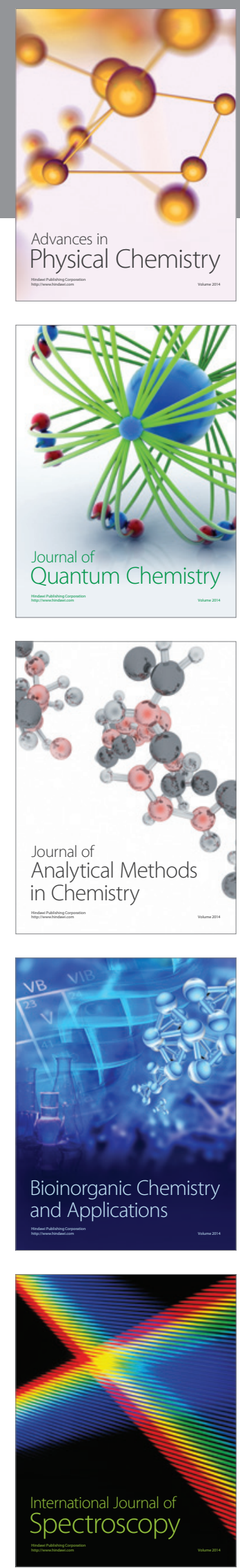